\title{
Granite Bainite Microstructure and Hardness of 30Cr3Ni2 Alloy Steel Prepared by Laser Direct Deposition
}

\author{
Xueting Chen ${ }^{a}$, Suiyuan Chen ${ }^{\text {b* }}$, Tingting Guanc, Tong Cui ${ }^{\mathrm{d}}$, Jing Liang ${ }^{\mathrm{e}}$, Changsheng Liu \\ Key Laboratory for Anisotropy and Texture of Materials (Ministry of Education), School of Material Science \\ and Engineering, Northeastern University, Shenyang 110819, China, \\ a410582806@qq.com, \\ b ${ }^{*}$ chensy@smm.neu.edu.cn, ${ }^{\mathrm{c}} 419321289 @ q q . c o m,{ }^{\mathrm{d}}$ cuit@smm.neu.edu.cn, ${ }^{\mathrm{e}}$ liangj@atm.neu.edu.cn, ${ }^{\mathrm{f}} \mathrm{csliu} @$ \\ mail.neu.edu.cn
}

Keywords: laser direct deposition; 30Cr3Ni2 alloy steel; microstructure; hardness; granular bainite.

\begin{abstract}
Cr3Ni2 alloy steel was prepared by laser direct deposition technology. The microstructures and hardness of the alloy steel were studied by metallurgical microscope, scanning electron microscope, energy dispersive spectrometer, X-ray diffraction, microhardness tester and transmission electron microscope. The results show that the microstructure of 30Cr3Ni2 alloy steel was composed of the grain boundary allotriomorphic ferrite/granular bainite (FGBA/BG), which the average hardness was 379HV. The phases of 30Cr3Ni2 alloy steel were mainly composed of $\alpha-\mathrm{Fe}$ solid solution, $\mathrm{M}_{7} \mathrm{C}_{3}$ and $\gamma$-Fe. This study paves the way for the further deepening of the research on alloy steel parts prepared by laser direct deposition.
\end{abstract}

\section{Introduction}

Laser direct deposition technology has been widely used in various fields with the characteristics of shaping fast and free without die, near net forming, manufacturing integration and low cost short process and so on [1-3]. Traditional technology needs to be replaced to prepare nuclear emergency diesel generator crankshaft, and new components need to be designed to accommodate laser direct deposition.

As one of the main constituent phases in steels, the formation mechanism of granular bainite have been well discussed. Z. Qiao and Y. Zhou's [4, 5] research results have shown that the bainitic ferrite matrix in the granular bainite exists in two forms: laths and polygons. P. Xu's study has shown that this polygonal bainitic ferrite can be called the grain boundary allotriomorphic ferrite. Compared with the single granular bainite, the FGBA/BG duplex microstructure has a better strength and toughness matching [6].

The aim of this study was to design a new type of alloy steel powder suitable for laser direct deposition. It is expected to obtain fine granular bainite microstructure with good formability, no cracks and high hardness, which can meet the performance requirements of nuclear emergency diesel generator crankshaft and enrich theoretical study on the method of preparing alloy steel parts by the laser direct deposition technology.

\section{Experimental Materials and Methods}

\subsection{Materials and methods of the samples preparation}

Table 1 is the chemical composition of $30 \mathrm{Cr} 3 \mathrm{Ni} 2$ alloy powder and the mean partical diameter of $30 \mathrm{Cr} 3 \mathrm{Ni} 2$ alloy powder is $200 \mathrm{um}$. In this experiment, the $30 \mathrm{Cr} 3 \mathrm{Ni} 2$ alloy steel sample was prepared under protection of argon gas in $0.2 \mathrm{Mpa}$ by the FL-Dlight02-3000W semiconductor laser, the spot of laser is $4.0 \mathrm{~mm} \times 4.0 \mathrm{~mm}$. The laser power is $2000 \mathrm{~W}$, defocusing amount is $4 \mathrm{~mm}$, scanning speed is $8 \mathrm{~mm} / \mathrm{s}$, overlapping rate is $30 \%$. Using the powder preplaced method, the thickness of each layer of 
powder is $1 \mathrm{~mm}$.

Table 1 The chemical composition of 30Cr3Ni2 alloy steel

\begin{tabular}{|c|c|c|c|c|c|c|}
\hline Elements & $\mathrm{C}$ & $\mathrm{Cr}$ & $\mathrm{Ni}$ & $\mathrm{Mn}$ & $\mathrm{Si}$ & $\mathrm{Fe}$ \\
\hline Content & 0.3 & $2.4-2.5$ & 1.8 & 0.5 & 0.4 & balance \\
\hline
\end{tabular}

\subsection{Experimental analysis}

The alloy steel sample prepared by laser direct deposition was corroded by $4 \%$ nitric acid alcohol, The characterization of the microstructure of the sample was carried out using a optical microscope (OM, OLMPUS-GX71) and scanning electron microscope (SEM, JSM-6510A) with an EDS analyzer and a transmission electron microscope (TEM, TECNAIG220). The phase identification of the sample was performed using an X-ray diffractiometer (XRD, PW3040/60) with $\mathrm{Cu}-\mathrm{K} \alpha$ radiation angle between $20^{\circ}-100^{\circ}\left(\mathrm{Vs}=2^{\circ} / \mathrm{min}, \mathrm{U}=40 \mathrm{KV}, \mathrm{I}=200 \mathrm{~mA}\right)$. The hardness data taken on the vertical sections of the sample was collected in a WILSON-WOLPER-450SVD microhardness tester at a load of $200 \mathrm{~N}$ and an indentation time of $10 \mathrm{~s}$.

\section{Results and discussion}

\subsection{Microstructure of 30Cr3Ni2 alloy steel}

Fig. 1 is the cross-section OM metallograph of 30Cr3Ni2 alloy steel in which typical columnar crystals and equiaxed grains can be clearly observed without cracks and pores. As we can see, there are more columnar crystals in the bottom area of the sample where near the junction. Correspondingly, the number of equiaxed grains in central region of the sample is more. This is because of the large temperature gradient at the beginning of the direct laser deposition process, which tends to lead to the formation of columnar crystals. As the deposition process progresses, the temperature gradient decreases and more equiaxed grains are formed by thermal cycling and heat accumulation.
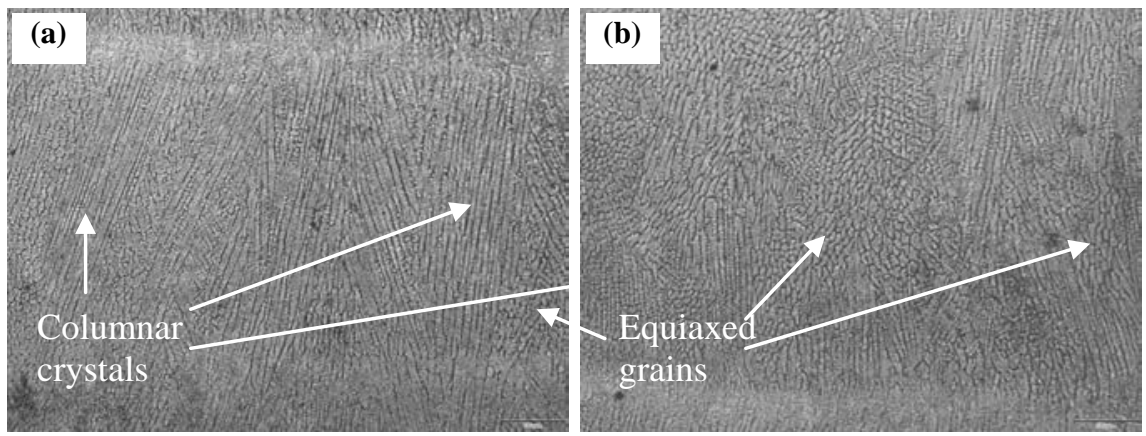

Fig. 1 The cross-section OM metallograph of 30Cr3Ni2 alloy steel by laser direct deposition(a)-bottom region of the sample; (b)-central region of the

Fig. 2 shows the SEM and EDS of 30Cr3Ni2 alloy steel by laser direct deposition. The phase composition of deposited sample is mainly granular bainite. As shown in Figure 3a, the M/A islands are granulated on the massive ferrite, and the FGBA/BG duplex microstructure can be clearly observed. According to the spot-scan analysis results shown in Table 2, the contents of $\mathrm{C}$, $\mathrm{Cr}$ and Fe

are high in the particle marked in Fig. 2(b) These elements are the main elements of the composition of M7C3, which indicates that the particle with a diameter of $1 \mu \mathrm{m}$ is a carbide particle. 

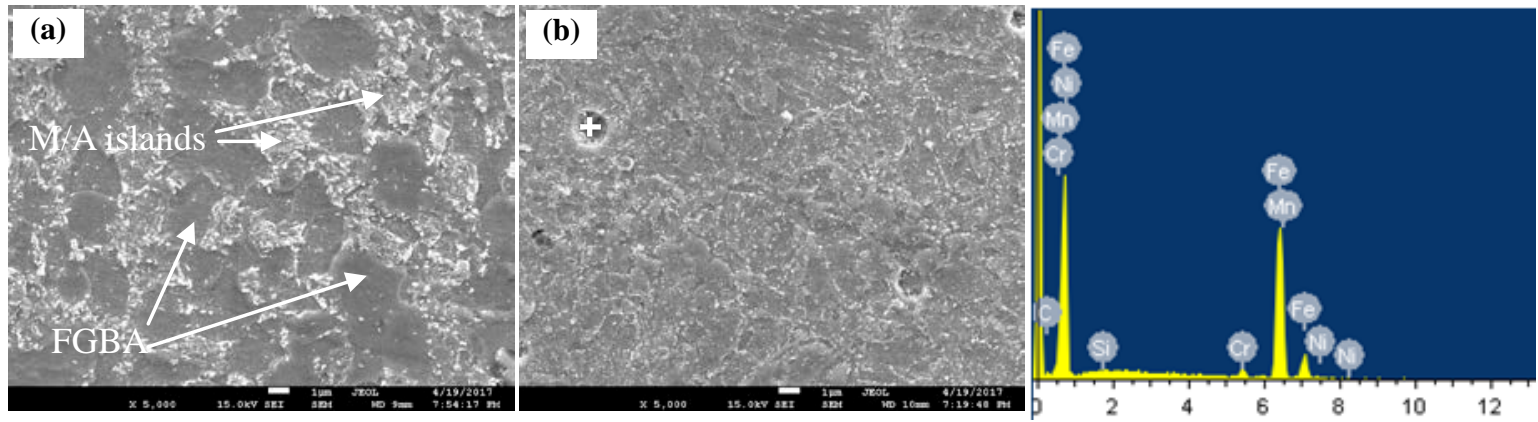

Fig. 2 SEM and EDS of 30Cr3Ni2 alloy steel sample by laser direct deposition

(a)-FGBA/BG; (b)-BG and EDS of the marked spot

Table 2 The EDS of the marked spot in Fig. 1(b)

\begin{tabular}{|c|c|c|c|c|c|c|}
\hline Element & $\mathrm{C}$ & $\mathrm{Cr}$ & $\mathrm{Ni}$ & $\mathrm{Mn}$ & $\mathrm{Si}$ & $\mathrm{Fe}$ \\
\hline Wt. \% & 2.20 & 2.12 & 0.67 & 0.07 & 0.10 & 94.84 \\
\hline
\end{tabular}

Fig. 3 shows the results of TEM observation of the 30Cr3Ni2 alloy steel sample. The selected area diffraction patterns (SADP) of the areas marked in Fig. 3 determine the presence of retained austenite and carbides in 30Cr3Ni2 alloy steel. The black areas as indicated by the arrow in Fig. 3(a) are $\mathrm{M} / \mathrm{A}$ islands, and the zone axis is [1-1-1]. There is a carbide particle with a diameter of $1 \mu \mathrm{m}$ as shown in Fig. 3(b), and the [21-3] zone axis corresponds to the M7C3 type carbide.
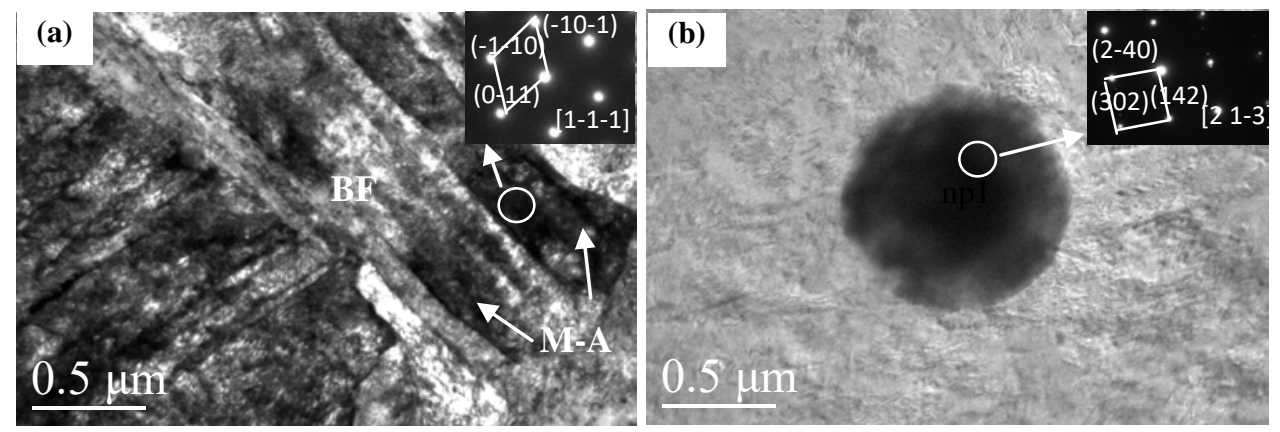

Fig. 3 TEM and EDS of 30Cr3Ni2 alloy steel sample by laser direct deposition(a)-micrograph of $\mathrm{BF}$ and M/A and SADP of the marked area; (b)-microphology of the carbide particle and its SADP

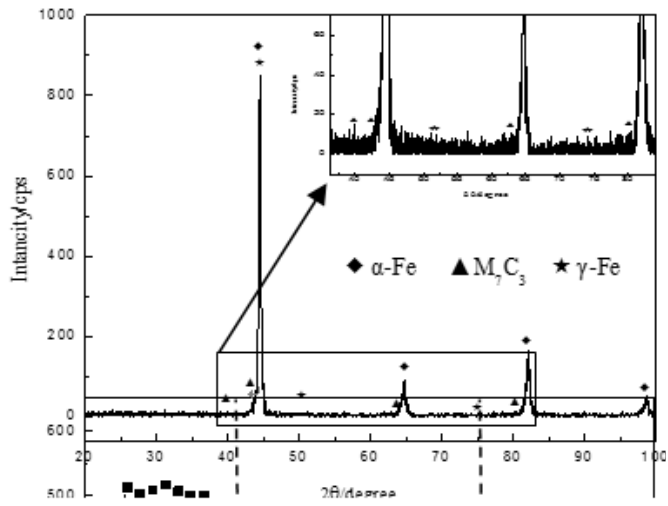

Fig. 4 XRD of $30 \mathrm{Cr} 3 \mathrm{Ni} 2$ alloy steel sample

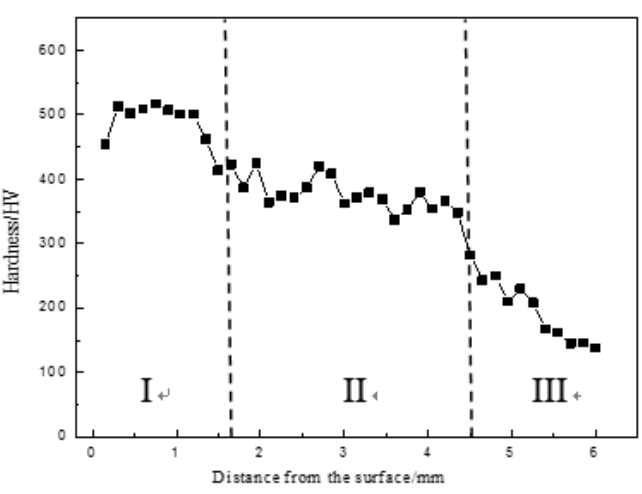

Fig. 5 The hardness curve of $30 \mathrm{Cr} 3 \mathrm{Ni} 2$ alloy steel by laser direct deposition

Fig. 4 shows the XRD analysis of 30Cr3Ni2 alloy steel by laser direct deposition. The diffraction peaks show that he grain structures of the $30 \mathrm{Cr} 3 \mathrm{Ni} 2$ alloy steel sample are Fe-Cr-Ni solid solution, $\mathrm{M}_{7} \mathrm{C}_{3}$ and $\gamma$-Fe. This result is consistent with the observations of the micrographs shown above, 
demonstrating that a small amount of retained austenite is present in the sample, and the circular particles marked in Fig. 2(b) and Fig. 3(b) are $\mathrm{M}_{7} \mathrm{C}_{3}$ particles.

\subsection{Hardness of 30Cr3Ni2 alloy steel}

Fig. 5 is the hardness curve of 30Cr3Ni2 alloy steel by laser direct deposition. The relatively stable curve corresponds to dense microstructures without cracks and pores. The curve can be distinguished into three parts. The part I is the area near the surface of the sample, the average hardness can be up to $500 \mathrm{HV}$. This is due to the rapid cooling rate at the near surface of the sample results in the formation of some number of martensite. Then the martensite was tempered and transformed into tempered martensite when heated by the next layer added on top of it, which is equivalent to the tempering process; The part II is the central region of the sample with a BG microstructure corresponds to Fig. 2 and its average hardness can reach $379 \mathrm{HV}$; The hardness curve is significantly reduced when it passes through the heat affected zone to the substrate, and the average hardness is $198 \mathrm{HV}$ in the part III, which is obviously lower than that of part II.

\section{Conclusions}

The 30Cr3Ni2 alloy steel sample was successfully prepared by laser direct deposition without cracks and pores. The phase structures of $30 \mathrm{Cr} 3 \mathrm{Ni} 2$ alloy steel are Fe-Cr-Ni solid solution, $\mathrm{M}_{7} \mathrm{C}_{3}$ type carbides and $\gamma$-Fe, and the size of $\mathrm{M}_{7} \mathrm{C}_{3}$ carbide particles are $1 \mu \mathrm{m}$. The average hardness of the BG microstructure in 30Cr3Ni2 alloy steel is $379 \mathrm{HV}$.

\section{Acknowledgements}

This work was financially supported by National Key R\&D Program of China (2016YFB1100201), National Natural Science Foundation of Liaoning United fund (U1508213), Science and Technology Plan Project of Liaoning Province (2014221006), and Science and Technology Plan Project of Guangdong Province (2015B010122001).

\section{References}

[1] S. Li, H. Xiao, K. Liu, W. Xiao, Y. Li, X. Han, J. Mazumder, L. J. Song. Mat. Des. 119 (2017) 351-360.

[2] M. Wei, S. Chen, J. Liang, C. Liu. Vacuum, 143 (2017) 185-194.

[3] S. Chen, H. Li, L. Liu, J. Liang, C. Liu. Advances in Engineering Research, 83 (2016) 259-263.

[4] Z. Qiao, Y. Liu, L. Yu, Z. Gao. Journal of Alloys and Compounds, 475 (2009) 560-564.

[5] Y. Zhou, T. Jia, X. Zhang, Z. Liu, R. Mat. Sci. Eng. A-Struct. 6256 (2016) 352-361.

[6] P. Xu, H. Fang, B. Bai, Z. Yang. R. Mat. Sci. Eng. A-Struct. 385 (2004) 65-73. 